\title{
1 Understanding Japan through the lens of Tokyo 2020
}

\author{
Barbara Holthus, Isaac Gagné, \\ Wolfram Manzenreiter, Franz Waldenberger
}

\section{The Games}

The average Olympic 100-meter dash finals are over in under ten seconds. The average Olympics and Paralympics last for a combined total of 34 days of events. The Olympiad - the period from one Summer Games to the next - lasts four years. And yet preparations in the hope of becoming a host city take many more years. In the case of Tokyo 2020, they have been ongoing for over 15 years, and the legacies after the Games - in the Tokyo cityscape, the nation's economy and the national memory - will last more than a lifetime.

For the brief span of July 24 to August 8 and from August 25 to September 6, 2020, Tokyo becomes the center of global attention, and all eyes are on what records will be broken and the new heights that the athletes from around the world will reach. Whatever new Olympic and Paralympic records might be set during the Games themselves, Tokyo 2020, as it is often called in Japan, has already been record-breaking in many ways. It will feature the most Olympic events ever spread across the widest geographical area, 33 different sports and disciplines with 339 events held in 42 venues up to 1,300 kilometers apart.

Furthermore, Tokyo 2020 has the largest projected costs in the history of the Olympics, at one point estimated at nearly $\$ 30$ billion, and later scaled down to $\$ 13.5$ billion. At the same time, Tokyo 2020 also secured the most sponsor-driven revenue in the history of the Olympics, with over $\$ 3.7$ billion secured in corporate sponsorships by June 2019. Tokyo 2020 writes also a new chapter in Olympic and Paralympic history for Japan, as well as for Asia. For Tokyo this will be the second time in 56 years to host the Summer Games, following the 1964 Tokyo Olympics - though in fact, this is technically the third time that Tokyo has been selected as host city, including the forfeited 1940 Tokyo "Phantom Olympics" that never came to be. Tokyo 2020 is thus the fifth time that an Asian city has been selected 


\section{Barbara Holthus et al.}

to host the Summer Games, and the fourth time that they are held in Asia, after Tokyo 1964, Seoul 1988, and Beijing 2008.

Whereas the 1964 Tokyo Olympics symbolized Japan's recovery from World War II, Tokyo 2020 is described as an opportunity to symbolize Japan's recovery from the so-called two lost decades of the 1990s-2000s and the massive devastation of the March 11, 2011 earthquake, tsunami, and nuclear meltdown in northeastern Japan. But more than simply displaying the nation's recovery - which itself has been questioned by many - Tokyo 2020 is also seen as a moment for reflecting and reimagining the nation.

After soul-searching about the place of Japan in the world amidst the political and economic rise of other nations in East Asia since the 1990s and the country's own economic stagnation, including losing its place as the number two economy in the world to China, the Japanese government has been looking for opportunities to show how Japan is still an important player in the world. The 2020 Tokyo Olympics and Paralympics are an opportunity for Japan to showcase its international standing and contribution, its cultural values and technological advancement, as well as its sporting prowess. Tokyo 2020 is constructed as an important moment of redefinition for the nation visà-vis the global community, as well as to itself and its people.

\section{The city}

Like the Olympics themselves, Japan's capital has displayed hyperbolic growth since 1964. Greater Tokyo, which includes the neighboring prefectures of Saitama, Chiba, and Kanagawa, is by far the biggest urban area on the planet with more than 35 million people. Tokyo proper, consisting of 23 inner wards and satellite cities in the West, had already bypassed New York as the world's largest city by 1955 . Up to 2020, Tokyo's population has grown by $30 \%$ to more than 13 million inhabitants, securing Tokyo a top rank among the world's mega-cities. Tokyo occupies less than $1 \%$ of Japan's total landmass, yet in 2020 is home to more than $10 \%$ of Japan's entire population and produces about $20 \%$ of its gross domestic product (GDP).

The demand for space of an ever-growing city has left its marks on the cityscape. All the islands in Tokyo Bay, as well as large parts of the seaside, are man-made reclamation projects, mostly by waste materials, sand from dredging, soil removed from construction sites and recently also by rubble from the disaster-stricken area in Tohoku. About two million tons of landfill were being dumped each year into the bay around the time of Tokyo 1964. The growth of annual disposal peaked in 1979, and has since fallen to levels well below 1964, thanks to waste reduction and recycling programs. 
In marked contrast to 1964, Tokyo in 2020 is one of the world's tallest cities, with more than 150 buildings exceeding a height of 150 meters. Within these multi-functional skyscrapers, $32 \%$ of the space is used for luxury residences. At the time of Tokyo 1964, the New Otani Hotel was the tallest building in the city with its 17 floors reaching 72 meters; by no means a skyscraper but even today a landmark in the cityscape. Bubbling real estate prices in the 1980s induced a great number of high-rise building projects. At the peak of the bubble, real estate prices for Tokyo's central Chiyoda Ward, covering less than $12 \mathrm{~km}^{2}$, surpassed the entire real estate value of Canada. Yet ironically the building boom took off only after the bubble burst. Nowadays the metropolitan area has thousands of buildings towering above the height of the old New Otani Hotel.

Tokyo managed to cope well with the challenges of rapid growth, once it started to tackle environmental issues that made life in the city difficult to bear following the 1964 Olympics. Nowadays, the world's biggest urban conglomeration has less air pollution, traffic jams, litter, and noise than any other mega-city. Tokyo citizens enjoy a safe environment, lots of green space, and the world's largest rail network of more than 150 lines, transporting 40 million passengers day by day. The Michelin Guide awarded the city's gourmet eateries the highest number of stars, heralding it as the world's culinary capital. In recent years Tokyo reinvented itself as the global Capital of Cool, with Harajuku, Shibuya, and Akihabara attracting Japanese popular culture fans and millions of other visitors from abroad.

The downside of Tokyo's success story is the widening gap with the rest of the country. Many in the regional peripheries are weary of decades of unipolarization and feel left behind by the steady promotion of the metropolitan area. It is here where criticism of Tokyo hosting the Olympics in 2020 was most pronounced. This criticism, together with the questioning of a pollution-free Tokyo or Japan when considering the problems of radioactivity due to the Fukushima Daiichi nuclear power plant meltdown, are however seldom visible in mainstream public discourse.

\section{The nation}

Widening regional disparities are not the only issue that Japan is confronted with. Back in the 1960s, the economic miracle was still unfolding with growth of real GDP at annual rates of $10 \%$ and higher, which was supported by a young and rapidly growing population. Entering the 1990s, annual growth declined to about $1 \%$, accompanied by a rapidly aging and - since 2010 - even shrinking population. Government debt has risen to record-high levels, although without reliance on foreign money; in comparison, close to $30 \%$ of US national debt is owned by foreign entities. 
Quite to the contrary, Japan remains the world's richest country in terms of net foreign assets. But the distribution of wealth and income has become increasingly uneven.

With income inequality and poverty rates above the OECD average, the image of a homogeneous middle-class society has vanished - even as citizens continue to see themselves as predominantly "in the middle" in terms of their own standards of living. Structural barriers continue to prevent the full integration of women and elderly workers into the labor market, which has seen a steady rise of non-regular employment. The government is well aware that to cope with the demographic challenge of low fertility, efforts need to be directed towards improving career opportunities of women, deepening international integration, and increasing productivity.

The fourfold increase in foreign tourists over the last seven years, mainly from China and Southeast Asia, is certainly impressive. The number of foreign workers, too, doubled over the last five years, although the $2 \%$ share in total employment remains very low in international comparison. The same can be said of direct investment by foreign companies in Japan. Its level of 4\% relative to GDP amounts to just one tenth of the OECD average of $40 \%$. Labor productivity has been more or less stagnant over the last 25 years and has fallen below the OECD average. This is surprising, because Japan spends more than most other OECD countries on research and development. The country has also one of the best-educated workforces. However, it seems not to be able to employ these excellent resources effectively. As a consequence, the government has been calling for a "workstyle" reform and it is betting on the digital transformation. Its framework of "Society 5.0" envisages a super-smart and fully inclusive society, where the cyber and the physical world are hoped to be "seamlessly integrated." Digitalization and connectivity are not only envisioned to close Japan's productivity gap, they are also expected to provide direct solutions in areas like disaster prevention and resilience, elderly care, regional revitalization, and climate change mitigation. But technology alone will not bring about the changes needed to secure welfare and sustainability. Leadership and entrepreneurship are indispensable when it comes to exploiting technological potentials and driving social and economic change. Fostering leadership and entrepreneurship is probably the most important, but also most difficult challenge Japan confronts.

\section{The book}

In this book, we situate the 2020 Tokyo Olympics within the social, economic, regional, political, and global changes of and challenges for Japan. The Olympics serve as a catalyst for important issues in contemporary 
Japanese society, and therefore, using the 2020 Tokyo Olympics as a lens onto the city and country is our ultimate goal. We aim to explain why Japan deals with the implementation of this mega-event the way it does. These Olympics are constructed as something that as its legacy is supposed to "only bring good" to the country: embrace diversity and inclusiveness in society, foster sustainability, boost Japan's economy, be a beacon of light to improve social cohesion, create a feeling of unity and of pride for the country, increase the willingness of its citizens to volunteer for the well-being of society. Explaining how the many stakeholders, institutions, average citizens, interest groups, and protest groups deal with this and forge their own roles, counter or not, vis-à-vis this mega-event helps in understanding how Japan works, far beyond the mega-event itself. Only a publication that takes this multitude of facets into account is able to show how deeply the Olympics impact society, politics, the economy, and public discourse already for years ahead of the Games.

The editors and authors gathered in this publication are wellpublished Japan scholars, from the fields of political science, sociology, economics, history, anthropology, linguistics, social geography, and cultural studies. They are connected to the German Institute for Japanese Studies, DIJ for short; they are either current or former researchers of the DIJ or scholars at other universities, who are linked to the institute through other joint research projects. The DIJ is a research institute focused on contemporary Japan, and is funded by the German Federal Ministry of Education and Research. It is located in the heart of Tokyo, right across from the New Otani Hotel mentioned above, the tallest building in Tokyo in 1964. The history of the DIJ dates back to 1988, just before the beginning of the Heisei period in 1989. As we write this book in 2019, with the abdication of Emperor Akihito and the ascension of Emperor Naruhito, we entered the first year of the so-called Reiwa period. With our mission to enhance knowledge and understanding of contemporary Japan through multi- and interdisciplinary approaches, we are uniquely positioned in providing insights into the discourses and debates, changes, and events connected to bringing the Olympic Games of 2020 to Tokyo for the second time since 1964.

The book offers "hidden" insights into the Games and provides a window onto Japanese society, economics, and politics through portraying the way the Olympic Games have influenced Japanese society, government, and businesses already for years before the Games have even started. City planning and host town organization, financial issues, language use, food, security concepts, sexuality and sexual policing, school activities, volunteerism, construction work, advertising the Olympics and the Olympic sponsor system, but also the struggle over food standards, as well 


\section{Barbara Holthus et al.}

as the implementation of diversity in regards to disabilities, sexual minorities and partnerships are just some of the issues taken up by chapters in the book. Longer chapters are interspersed with one-page spotlights that highlight additional key issues, among them technological innovations planned to be showcased for the Olympics, the struggle with fighting Tokyo's extreme summer heat, and the Olympic mascots. We also give short glimpses of the new Olympic sports and the role of these sports in Japan.

As foreigners, non-Japanese, we have an outsider's view onto Japan and Tokyo. Yet as Japan scholars, speaking Japanese, and being long-term residents in Tokyo, we also have the privilege of an insider's perspective. This makes us especially suited for publishing this book, in more depth than foreign journalists can and with more insight than scholars who reside outside of Japan. This book is our attempt to explain Japan to those without much prior knowledge of Japan; be it university students or a generally interested audience alike. The book is illustrated with numerous images taken throughout the city to show the infiltration of the Olympics throughout the cityscape and throughout everyday urban life - be it at school entrances, in train stations, on streets, in stores, and more. Constant bombardment of Tokyo 2020-related advertising weaves through the entire fabric of social, public life.

The city and its public transport system are plastered with posters and videos in trains or on platforms for the millions of daily commuters taking one of the many lines of Tokyo Metro, one of the main local sponsors of the Olympics; numerous campaign events are held throughout the city; countdown markers can be found throughout the city in sightseeing spots, public buildings, or shops (see Figure 0.2); Olympic logos are a daily sight in the rows of products in supermarkets, displayed on sponsors' goods such as chocolate, milk, or yoghurt; TV reports help in explaining the Paralympics, the hurdles and endurance of Olympic and Paralympic hopefuls; Japanese fictional TV-series (terebi dorama), advertisements, museum exhibits, and anti-Olympic demonstrations (even though small) also do their part in cementing the Olympics into the consciousness and memory of those within the city, if not beyond. The building boom in the city further underlines this. The "Go Beyond 2020" campaign is one such marketing example, hinting at the legacy and sustainability of the Games for the citizens of Tokyo - an improved infrastructure, aiding diverse needs for those in wheelchairs or for parents with strollers (see Figure 1.1).

As the following pages show, the book provides a fascinating window onto Japan as a whole, not just the mega-event itself. The Olympics are so much larger than the four weeks themselves. This book is actually about Japan 2020, it guides through the developments and also points to 


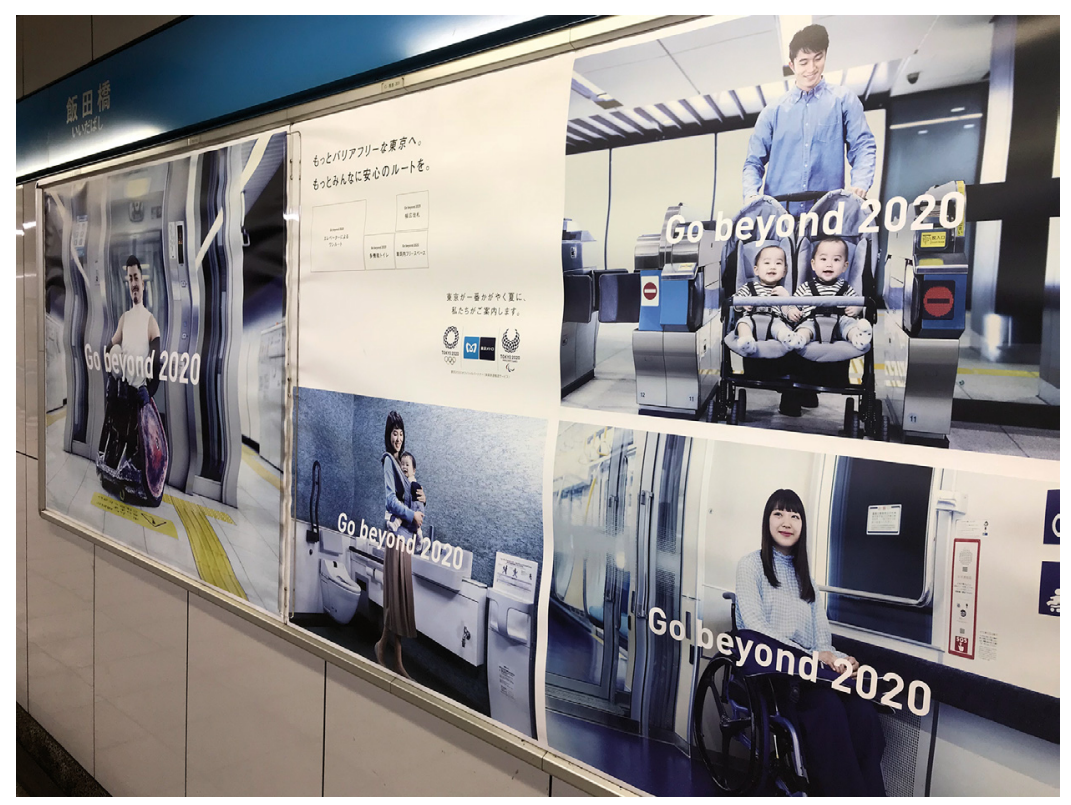

Figure 1.1 Advertising a more barrier-free Tokyo, by Tokyo Metro.

Source: (C) Barbara Holthus.

post-Olympics Japan and Tokyo - when the Olympic tourists have left, when hotel prices will have leveled off again, when companies can run their operations smoothly again without the significant hindrances of masses maneuvering through the city to get to the Olympic venues, when the apartments in the Olympic Village will be getting ready to be turned over to their new tenants, and when politicians and historians start reflecting on the Games, and when the actual costs will come to light. And then it is already time for Japan to start gearing for its next mega-events, such as the World Masters Games 2021, held in the Kansai region and for the first time in Asia, as well as the 2025 Osaka World Expo. Tokyo 2020 is certainly a major horizon; but as the city itself expands beyond the limits of one's vision, the future of Tokyo - and Japan - stretches far beyond the halo of the Olympic torchlight. 